ice when they set off for the fishing grounds, each boat taking about 15 tons when going to fish in the North Sea and four times as much when fishing in Icelandic waters. In the Metropolitan-Vickers Gazette for March and April, J. H. Lamb gives an interesting account of the electrification of the factory. The plant is capable of turning out 1,200 tons of crushed ice a day and delivering it into the holds of the fishing vessels by means of a fleet of motor lorrics. Before reconstruction, the plant was driven by ponderous slow-speed engines. It has now been replaced by electrically driven compressors and all the auxiliary equipment has been completely electrified. The refrigerating medium is ammonia and the ammonia gas is raised in the compressors to a pressure of between $100 \mathrm{lb}$. and $180 \mathrm{lb}$. per sq. in. It is next cooled and liquified by passing through a condenser. The liquid then passes to the refrigerating plant in tubes surrounded by brine. The liquid. expanding to its gaseous form absorbs heat from the brine which is cooled below $0^{\circ} \mathrm{C}$. The cold brine is circulated in a large tank containing the cans which hold the pure water to be frozen. The four compressors are driven by four motors each of 600 horse power. These are supplied with electric power by the Grimsby Corporation, through a transmission line at 6,300 volts. The Ice Company is developing a new process of freezing which it is hoped will popularise frozen fish. Complaints have been made that frozen fish are 'soft' or 'mushy' when thawed. By rapidly freezing them the water between the flakes of the fish does not crystallise and when thawed it is stated that the fish is just as firm and white as fresh fish.

\section{Progress at the Indian Institute of Science, Bangalore}

ThE April number of Electrotechnics, the journal of the Electrical Engineering Society of the Indian Institute of Science at Bangalore, proves that rapid progress is being made in developing its activities. It has been decided to instal in the Electrical Department a radio frequency standard which will enable measurements to be carried out with the highest accuracy over a range extending from 10 to 24,000 kilocycles per second. The Government of India will recognise the Institute's certificates. It is hoped that this will prove the first step towards the establishment of a National Physical Laboratory of India. An obituary notice of the late Dr. Alfred Hay, who was appointed to the chair of electrical technology at the Institute in 1908, appears in this issue. Many of his students have done good work in electrical research. He was sadly missed by them when he left for England in 1923. He died in Cyprus in 1932. $\mathrm{He}$ was succeeded by Prof. J. K. Catterson-Smith, who is now Siemens professor of electrical technology at King's College, London. He did excellent work in developing radio research at Bangalore. Sir C. V. Raman became director of the Institute in succession to Dr. M. O. Forster, whose well-merited knighthood announced among the King's birthday honours will give particular pleasure to his friends. An interesting account is given of the Uhl River hydro-electric scheme. The combined output of the power stations will be 150,000 kilowatts. From an article by C. B. Sethna, director of the Bombay broadcasting service, on the progress of broadcasting in India, it appears that Calcutta, Bombay and Madras have now a regular broadcasting service. What is wanted seems to be a few high-power broadeasting stations at the centres of culture of the important linguistic areas of India.

\section{Exchange of Goods during Economic Depression}

REVFiRsions to simpler types of economic organisation are not uncommon in times of economic stress, and an interesting example is provided by the development of the exchange of goods and services by barter in the United States during the present economic depression. In 1931 a small exchange was opened in Salt Lake City to facilitate the barter of unemployed labour for surplus farm produce. Since then, the movement has spread rapidly to many parts of the country and now covers a wide range of trades and professions. A National Development Association was formed to organise the exchanges, and in July 1932 this body introduced a medium of exchange in the form of paper tokens known as 'scrip'. This 'scrip' represents to the holder the value of the produce or services he has provided and can be exchanged for an equal value of other produce, being readily accepted by traders, shops and theatres. 'The issue of 'scrip' is, however, far from being an innovation in the United States, and recently Mr. T. T. Belote, curator of history in the Smithsonian Institution, arranged an interesting exhibition of earlier examples. During the decade 1832-42, numerous bank failures led to much money being withdrawn from circulation, and to meet the monetary stringency a large number of so-called 'hardtime tokens' were issued. Some of these bore laudatory or satirical legends referring to the financial policies of Jackson or Van Buren. In the same period, many commercial firms issued a kind of token money known as 'store cards'. Up to the Civil War, paper scrip issued by banks and private firms of almost every imaginable character circulated extensively. Some of it was well-drawn and finely engraved, but so rapidly did many of the issues deteriorate in value that they came to be known as 'skin plasters'.

\section{B.D.H. Products}

WE have received from the British Drug Houses Ltd., London, N.1, leaflets describing the nature and uses of certain of their products. 'Spironine', a stable elixir, contains in each fluid drachm 3 grains of di-iodo-caffeine hydroiodide together with the soluble constituents of $7 \frac{1}{2}$ grains of coffee. It is recommended for the relief of asthma during the intermittent paroxysms. It should be given at the onset of an attack, its effect being immediate. By checking the paroxysms it prevents the development of such chronic conditions as emphysema and bronchitis. Another drug of great value in the treatment of asthma is 'Ephedrine', which also finds a place in 